\title{
LONG-TERM FOLLOW-UP OF PARAPLEGIC PATIENTS WITH VESICO-URETERIC REFLUX
}

\author{
By G. J. Fellows, M.S., F.R.C.S. and J. R. Silver, M.R.C.P.(E.) \\ National Spinal Injuries Centre, Stoke Mandeville Hospital, Aylesbury
}

\begin{abstract}
VESICO-URETERIC reflux and urinary infection are frequently associated, although there is debate as to which is cause and which effect. Sometimes reflux ceases when infection is treated (Amar, 1975), but frequently the reflux persists and infection is difficult to eradicate. One of the main causes of aquired vesicoureteric reflux in the adult is injury to the spinal cord. Anti-reflux surgery was first developed for the treatment of reflux in patients with spinal injuries, but the results have been disappointing in this condition. Many patients with reflux are treated with permanent urethral catheters. Although it is well known that reflux is often associated with attacks of recurrent acute pyelonephritis, the longterm effects of reflux are not well documented.

Marchetti and Gonick (I970) have shown diminished renal function in patients with reflux compared with controls.

The purpose of this survey was to assess the long-term effects of reflux in patients with spinal injury treated at The National Spinal Injury Centre, Stoke Mandeville.
\end{abstract}

\section{Patients and Methods}

\section{Criteria of Reflux}

Reflux is described in three grades:

Grade I: into the ureter only;

Grade 2: reaching the renal pelvis and calyces, but without dilatation of the ureter or pelvi-calyceal system;

Grade 3: extending to the kidney with dilatation of the upper urinary tract.

\section{Patients}

A retrospective survey has been carried out including all patients with grade 2 or 3 reflux detected within I year of injury, admitted to Stoke Mandeville from I944 to I963. They were all patients with traumatic cord injury. Details of their age, sex, completeness of cord lesion and delay in admission to Stoke Mandeville are summarised below. If possible the patients attended for review, but if unable to travel to hospital, information was obtained from the patient's doctor or local hospital. As complete a record as possible was obtained of the patient's urinary tract from the time of his injury to the present day. The features recorded included the following: sex, age at time of injury, level of lesion, time from injury to admission and from injury to the detection of reflux, the initial bladder management, urinary infection before the detection of reflux, surgery to the bladder outflow tract, bladder management at home, severity and frequency or urinary infection, prophylactic chemotherapy. Blood was obtained for urea 
and creatinine estimation. All X-rays of the urinary tract on each patient were reviewed by one assessor (G. J. F.). When patients had died the date and cause of death were recorded. Patients were classified as having renal damage or no renal damage.

\section{Renal Damage}

The criteria for renal damage were: death from renal causes; urographic signs of upper tract dilatation, clubbing of calyces, or renal scarring; diminution of renal length of 20 per cent or more on X-ray. When comparing renal lengths on different urograms the width of a suitable lumbar vertebra was compared in the two urogram series to correct for differences in projection.

No living patient was found to have a plasma urea or creatinine outside the normal range. Whenever subsequent cystograms were performed reflux was recorded as either transient (present on one occasion only) or persistent (present on more than one occasion). The initial cystograms on which a diagnosis of reflux was made were usually performed because of persistent or recurrent urinary tract infections. They were static cystograms, continuous screening was not used at that time.

\section{Results}

Fifty-one patients fulfilled the criteria for inclusion in the survey. There were inadequate data regarding the renal tract in 12 leaving 39 patients for review. The reasons for excluding the 12 patients from analysis were as follows: four died of either unknown causes or causes unrelated to the renal tract without any further urological assessment, in one patient there was incomplete information about bladder management, five patients could not be traced and two had emigrated.

Of the 39 patients with complete data, I7 showed signs of renal damage. Four of these died of renal causes, a further one died of unknown cause but with a grossly dilated, virtually non-functioning kidney on the side of reflux, one patient is alive with shrunken kidneys, the remaining II are alive with urographic signs of upper tract dilatation, clubbing or renal scarring. There was no marked difference in the age (mean 30 years), sex distribution and mean period of followup between patients with or without evidence of renal damage. The mean followup for those with renal damage was 12.5 years and I 3 years for those without renal damage. Patients with renal damage had a longer delay from injury to admission to Stoke Mandeville than those without renal damage ( 9 and 5 weeks respectively). This might suggest that renal damage was consequent to inadequate treatment at the referral hospital. However, the small numbers in this series and the considerable variation in delay of referral in both groups of patients means that this conclusion may well be fallacious.

Reflux occurred with lesions at all levels of the spinal cord and when the lesion was both complete or incomplete (Table I).

Nineteen patients had bilateral reflux, I I right side only and nine left sided. There was no significant preponderance of bilateral reflux in the group with renal damage. There appeared to be a tendency for kidneys to diminish in length with time although in only two instances did this shrinkage amount to 20 per cent of the original length (Table II).

All patients had an initial urogram at about the time that reflux was first diagnosed. In 32 patients the initial urogram was entirely normal and in four 
TABLE I

Level and completeness of cord lesion in patients with reflux

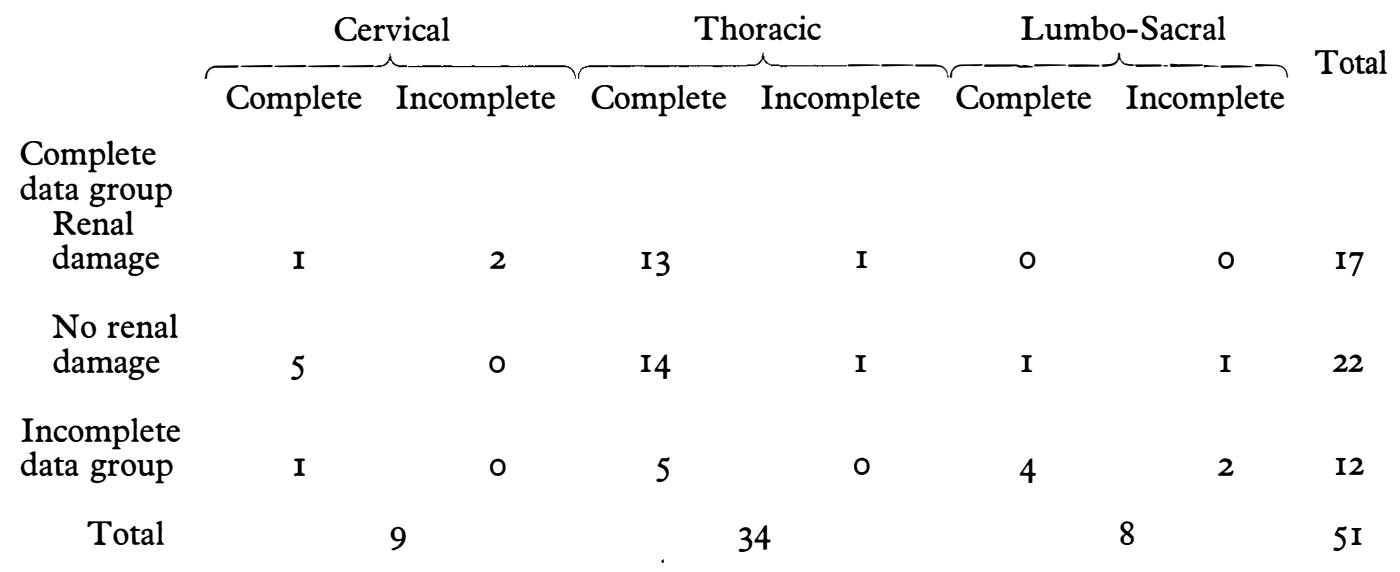

\section{TABLE II}

Change in length of kidneys on the side of reflux

Percentage change in renal length

$\overbrace{+20}+10 \quad-\overbrace{\text { No change }}^{-10} \quad-20 \quad \begin{gathered}\text { No assessment } \\ \text { possible }\end{gathered}$

Number

I

$3 \quad 17$

I5

2

20

Total of 58 kidneys from 39 patients. Reflux was bilateral in I9.

there was dilatation of the lower ureter. Three patients showed dilatation of the upper urinary tract; one showed improvement 8 years later without any treatment; one showed deterioration 8 years later also without treatment; one patient who showed the greatest degree of initial dilatation underwent transurethral resection of his bladder neck. Four years later the urinary tract had returned to normal.

\section{Factors Associated with Renal Damage}

Renal damage developed in five out of seven patients with initially grade 3 reflux, but in only I 2 out of 32 with grade 2 (Table III). The results also suggest that there may be an association between renal damage and both persistence of reflux and the presence of a urethral catheter although these do not reach statistical significance (Table III). Tables IV and V show that when the patients are grouped according to the grade of reflux or duration of reflux, those treated without catheters appeared to develop less renal damage than those with catheters. Although these values do not reach statistical significance the results fail to show any protection afforded to the kidneys by indwelling catheters.

There was no association between the frequency of urinary flare-ups during the follow-up period and the development of renal damage. There was a suggestion of an association between renal damage and urinary flare-ups before reflux was diagnosed. 
TABLE III

Renal damage related to grade and persistence of reflux and presence of urethral catheter

$\overbrace{\text { Total }}^{\begin{array}{c}\text { Grade of } \\ \text { reflux }\end{array}} \overbrace{3}^{\begin{array}{c}\text { Urethral } \\ \text { catheter }\end{array}} \overbrace{\text { No } \text { Yes }}^{\text {Reflux }} \overbrace{\text { Transient Persistent Not known }}^{\text {Rew }}$

$\begin{array}{lrrrrrrrr}\text { Renal damage } & 17 & 12 & 5 & 8 & 9 & 5 & \text { 10 } & \mathbf{2} \\ \text { No renal damage } & \mathbf{2 2} & 20 & 2 & 16 & 6 & 9 & 6 & 7 \\ \quad \text { Total } & 39 & 32 & 7 & 24 & 15 & 14 & 16 & 9\end{array}$

TABLE IV

Renal damage related to the grade of reflux and the presence of a catheter

$\overbrace{\text { No catheter }}^{\text {Grade } 2 \text { reflux }} \overbrace{\text { Catheter catheter }}^{\text {Grade }} 3$ Catheter

Renal damage

No renal damage
3
14
9

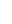
7 9 
and those with milder infections without catheters. No anti-reflux surgery was performed on these patients.

An indwelling urethral catheter although useful in the management of acute urinary flare-ups secondary to reflux does not protect the kidney from subsequent damage. Reflux to the kidney with dilatation of the upper urinary tract (grade 3 reflux) is particularly liable to precede renal damage. It is possible that these patients' upper tracts are damaged on account of the high intravesical pressure either at rest or particularly on voiding. As long ago as 1960, Ross et al. (1960) showed that reflux would often be abolished by decreasing urethral resistance. When reflux is diagnosed every effort should be made to detect and correct bladder outflow tract obstruction and eliminate infection (Tarabulcy et al., 1972). Even when reflux is persistent, provided flare-ups are not a problem, patients are better treated without permanent urethral catheters.

\section{SUMMARY}

A long-term survey (mean follow-up > I2 years) is presented of cord injury patients with reflux up to the kidney (grades 2 and 3). Of 39 patients 17 developed renal damage. There is no evidence that permanent urethral catheters protect kidneys from subsequent damage.

\section{REFERENCES}

AMAR, A. D. (1975). Eradication of reflux in adults by excision of chronic infection resevoirs without anti reflux operation. Fournal of Urology, I13, I75-I77.

MARChETTI, L. J. \& GoNICK, P. (I970). A comparison of renal function in spinal cord injury patients with and without reflux. Fournal of Urology, 104, 365-367.

NYQuIST, R. H. \& BoRs, E. (I968). Mortality and survival in traumatic myelopathy during nineteen years from 1946 to 1965 . Paraplegia, 5, 22-48.

Ross, J. C., Damanski, M. \& Gibbon, N. O. K. (I960). Ureteric reflux in the paraplegic. British fournal of Surgery, 47, 636-642.

Tarabulcy, E., Morales, P. A. \& Sullivan, J. F. (1972). Vesico-ureteric reflux in paraplegia: results of various forms of management. Paraplegia, 1 o, 44-49.

Wilcox, N, E. \& StAUfFer, E. S. (I972). Follow up of 423 consecutive patients admitted to the Spinal Cord Centre, Rancho Los Amigos Hospital, I January to 3I December, 1967. Paraplegia, 10, I I5-I22. 